\title{
Factor Analysis: Investigating Important Aspects for Agile Adoption in Malaysia
}

\author{
Ani Liza Asnawi, Andrew M. Gravell and Gary B. Wills \\ School of Electronics and Computer Science, \\ University of Southampton \\ SO17 1BJ, United Kingdom \\ \{ala08r, amg, gbw\}@ecs.soton.ac.uk
}

\begin{abstract}
This paper focuses on identifying the important aspects of Agile adoption from software practitioners in Malaysia. We analyse 27 Agile adoption variables from a survey of early Agile users in Malaysia. Factor analysis is conducted to identify the clusters of the variables (or items) and how they are inter-related to produce factors. Most of the respondents are from software organisations in Kuala Lumpur and Selangor; in which most of the companies are located in Malaysia. The clusters of variables resulting from this analysis can serve as a reference to the practitioners planning to adopt the methodology. The top factors identified from this study are shown in terms of (i) developer involvement and organisation-related aspects, (ii) cultural and people related aspects and (iii) customer collaboration and the need for professional skills when using Agile methods. In addition, factor analysis discovered that practitioners disagreed about the importance of the technical aspects of Agile. While we believe that these findings are particularly important from the Malaysian perspective, however, they also help add to the body of evidence in the field of software engineering and software process particularly in terms of Agile methods adoption. Moreover, the study also can help adopters from the nearby geographical regions to understand and see the suitability of Agile methods for their organisations.
\end{abstract}

Keywords-Agile methods; software process; factor analysis; loadings; factor extraction; factor rotation

\section{INTRODUCTION}

We analyse factor analysis from variables of Agile adoption responded by software practitioners in Malaysia. Factor analysis was conducted to understand the dimensions and meaning of the variables from our questionnaire. In addition, factor analysis can help to provide a summary for data inter-relationship and places those variables into their groups accordingly.

To see how Agile adoption variables in our study are inter-related, 27 questions regarding Agile adoption were asked to software practitioners in Malaysia. This questionnaire was posted online and also distributed to the participants attending the Scrum workshop and Scrum Product Owner workshop in Malaysia ${ }^{1}$. We believe that their stated interest in the methods and their intentions to adopt them will help us to identify the significance aspect for the adoption of Agile methods. Moreover, we ensured

${ }^{1}$ http://www.atsc.org.my/ (last accessed Sept 2011) that these 27 variables were only answered by practitioners that have experience in at least one Agile project.

\section{DATA COLLECTION AND ANALYSIS}

The questionnaire was posted online using Web SurveyMonkey ${ }^{2}$. We received a total of 207 responses, and 88 completed sections $\mathrm{B}$ and $\mathrm{D}$, which were therefore included in the factor analysis. This number is considered reasonable for this type of study received from this country [1] and from the region [2]. Furthermore, due to the early stage of Agile methods in Malaysia, this resulted in fewer respondents to this study of Agile methods. The data were analysed using SPSS version 17. Each variable for this analysis has a six point Likert-type scale; from strongly disagree (which is equal to one) to strongly agree (which is equal to six).

\section{SAMPLE SIZE AND STRENGTH OF RELATIONSHIP}

The suitability and appropriateness to conduct factor analysis with the data need to be checked [3]. There are two main issues to be considered when determining for the suitability of the data; one is in terms of sample size, and the other is the strength of relationship among the variables.

The common rule for the sample is to suggest that a study has at least 10-15 participants per variable which total 300 [4]. Another reference said that if a factor has four or more loadings greater than 0.6 then it is reliable regardless of the sample size [5]. One alternative to identify whether the data are suitable for factor analysis is by looking into the strength of inter-correlations among the variables. One of the statistical measures used to identify this is called Kaiser-Meyer-Olkin (KMO); a measure of sampling adequacy which ranges from 0 to 1 [6]. If the value yields more than 0.7 , then the correlation on the whole are sufficient to make factor analysis suitable. Values between 0.5 and 0.7 are mediocre, values between 0.7 and 0.8 are good, values between 0.8 and 0.9 are great and lastly values above 0.9 are superb [7]. A $\mathrm{KMO}$ with 0.6 is suggested as the minimum value for a good factor analysis [8]. As measured from the sample, a KMO value of 0.755 was obtained from our data.

\footnotetext{
${ }^{2}$ http://www/surveymonkey.com/s/2GMD8ZX
} 
Therefore it is justified that the factor analysis is suitable for these data sets.

\section{FACTOR EXTRACTION}

Factor extraction is one of the procedures in factor analysis. It involves determining the smallest number of factors (or components) that can best represent the interrelations among the sets of variables. In this analysis, principal component analysis is used as the extraction method. In order to determine how many numbers of factors (or components) are extracted, eigenvalues (or Kaiser criterion) and scree plot [3] are two sets of information that can be referred to. The first method, eigenvalues or Kaiser's criterion will extract and retain the factors that have eigenvalues greater than 1 for further investigations. Table 1 sumamarises the factors that have eigenvalues greater one (factor 1 to 8 ).

TABLE I. EIGENVALUES AND TOTAL VARIANCE EXPLAINED

\begin{tabular}{|l|l|l|l|}
\hline $\begin{array}{l}\text { Factor (or } \\
\text { component) }\end{array}$ & $\begin{array}{l}\text { Eigenvalues } \\
\text { (Total) }\end{array}$ & $\begin{array}{l}\text { Eigenvalues } \\
\text { (\% of Variance) }\end{array}$ & $\begin{array}{l}\text { Eigenvalues } \\
\text { (cumulative \%) }\end{array}$ \\
\hline 1 & 7.852 & 29.080 & 29.080 \\
\hline 2 & 2.534 & 9.385 & 38.465 \\
\hline 3 & 1.937 & 7.173 & 45.637 \\
\hline 4 & 1.638 & 6.067 & 51.704 \\
\hline 5 & 1.543 & 5.716 & 57.420 \\
\hline 6 & 1.182 & 4.378 & 61.798 \\
\hline 7 & 1.080 & 4.000 & 65.798 \\
\hline 8 & 1.028 & 3.809 & 69.607 \\
\hline 9 & 0.890 & 3.295 & 72.902 \\
\hline. &. &. &. \\
\hline. &. &. &. \\
\hline 27 & 0.093 & 0.344 & 100.000 \\
\hline
\end{tabular}

Scree Plot is shown in figure 1.



Figure 1. Scree Plot.

On the other hand, using the scree plot, the point at which the curve changes direction and becomes horizontal is checked. As described above, the scree plot suggests retaining only components above this point (figure 1).

\section{INTERPRETATION FOR THE FACTORS WITH THE RELATED VARIABLES}

There are two techniques in rotating factors; orthogonal (varimax) and oblique (oblimin). In order to see which rotation technique is appropriate for our data, we tried both orthogonal and oblique techniques [9]. In oblique rotation, the pattern matrix contains the factor loadings after the rotation while the structure matrix describes the relationship between the factors. The interpretation is mainly completed from the pattern matrix; however the structure matrix is useful for the purpose of double checking [3]. List below provides summary for the eight factors and their related variables.

\section{A. Factor 1: The Related Variables with their Loadings}

- Software developers have responsibility related to organisation's Agile activities $=0.816$

- Software developers are actively involved in setting goals for Agile activities $=0.805$

- In our software development, identifying project scope and suitability of project is important when using Agile methods $=0.674$

- In our organisation we are encouraged to be open and transparent at all levels $=0.497$

- Our organisational environment is a personal place where people share a lot of themselves $=$ 0.564

\section{B. Factor 2: The Related Variables with their Loadings}

- We have mixed races in our organisation/team (Malay, Indian, Chinese and other races) $=0.845$

- In our organisation, we communicate in English language $=0.810$

- In my experience, a mindset change when using Agile is important as Agile practice is different from other software methodologies $=0.434$

\section{Factor 3: The Related Variables with their Loadings}

- In our software development, customers are actively involved in setting goals for our Agile activities $=0.680$

- In my experience, practitioners with professional skills are needed when practicing Agile $=0.656$

- In our software development, customers have responsibility related to the organisation's Agile activities $=0.615$

- In my experience, when practicing Agile, customers also have knowledge of the methods = 0.556

\section{Factor 4: The Related Variables with their Loadings}

- I see customers' satisfaction when using Agile methods $=0.881$

- Our software development becomes easier because both parties (customers and developers) are working together when using Agile $=0.867$ 
- I see Agile boost developers' morale $=0.585$

- In software development, Agile methods provide quicker results $=0.495$

\section{E. Factor 5: The Related Variables with their Loadings}

- In my experience, training helps correct practice of Agile methods in our organisation $=-0.879$

- In my experience, continuous learning helps knowledge transfer occurring when using Agile methods $=-0.811$

\section{F. Factor 6: The Related Variables with their Loadings}

- In my experience, Agile methods are suitable for certain technology $=-0.943$

- In my experience, tools are important to support the usage of Agile methods $=-0.507$

- Our organisation emphasises on achievement and goal accomplishment where aggressiveness and winning are common themes $=-0.414$ (removed from the factor)

\section{G. Factor 7: The Related Variables with their Loadings}

- Our organisational environment is a personal place where people share a lot of themselves $=$ 0.614

- In my experience, I think, knowledge about Agile should be widely increased in the country $=-0.530$

\section{H. Factor 8: The Related Variables with their Loadings}

- In my experience, knowing roles and responsibilities is essential when practicing Agile methods $=0.694$

- In my experience, attitude (such as team spirit and team commitment) is required from everyone when developing software using Agile methods $=0.515$

- In our software development, Agile methods provide quicker results $=0.493$

Some variables are shown to have values of negative loadings. A negative sign of loading does not indicate any meaning regarding the strength of the variable to the factor. However, it gives meaning that the variable is related in the opposite direction with the factor [10].

\section{Discussion and Meaning For the Factor}

1) Factor 1: This factor shows the importance of the organisational aspects agreed by the Agile adopters in Malaysia. These include two loadings showing the importance of software developers' roles and responsibilities and their involvement when applying Agile methods. These two loadings about software developers are higher than the other loadings in the factor. Besides, it is also agreed that the scope and suitability of the project needs to be emphasised. The organisational aspect is also concerned with the environment, openness and transparency within the organisation. Having these loadings, factor 1 is interpreted as 'Developer Involvement and Organisation-related Aspects'.

2) Factor 2: The second factor is loaded by three variables. The highest loadings tell us that the adopters have mixed races in their organisations. This factor indicates that mixed races in an organisation or a team is not a problem when introducing Agile methods as the loading is high enough for that variable to the factor. From the loadings, it can be seen that adopters are using the English language. The factor also describes that changes in the working mind set is important when practicing Agile. It is considered reasonable to name these three loadings as 'Organisational Culture and People Related Aspects'.

3) Factor 3: The third factor resulting from factor analysis tells us about the customer-related aspect. A variable, 'In my experience, practitioners with professional skills are needed when practicing Agile' shows that the practitioners must have professional skills such as communication skills when dealing with the customers. Besides, it is also suggested that customers should have a professional skill such as soft skill for describing their software requirements. The rest of the loadings in this factor are clearly showing the importance of the customers' role including the knowledge of Agile methods that they need to have when practicing the method. This factor is interpreted as 'Customer Involvement when Practicing Agile methods'.

4) Factor 4: The factor contains loadings that provide meanings about benefits or positive impact when using Agile methods. The benefit ranked highest in terms of importance is shown in customers' satisfaction, followed by the results from work collaboration between customers and developers in Agile. Then the impact of Agile methods was also seen in the way it boosts the developers' morale and provides quicker results in software development. The factor also tell us that the practitioners agreed that Agile methods help them to deliver quicker development. Therefore, these four loadings are interpreted as 'Benefits/Impact when using Agile methods'.

5) Factor 5: This factor has two loadings representing the importance of training and learning when using Agile methods in Malaysia. However the loadings have negative values; an indicator that the items are describing the opposite sides of the factor. Alternatively, the negative values can be changed to positive values; but the wording of the loadings must be reversed. For example 'In my experience, training helps correct practice of Agile methods in our organisation' $=-0.879$ can have positive value by reversing it to 'In my experience, training does not help correct practice of Agile methods in our 
organisation' $^{\prime}=0.879$. The variables in this factor suggest disagreement about the importance of training and learning when using Agile methods in Malaysia. Most respondents are those who attending the training when the questionnaire was given. This might be one reason for the disagreement as they were undergoing training while answering the questions. Because of that, they still would not know whether training can help them to use Agile correctly.

6) Factor 6: Factor six is showing loadings about the technical or technological aspects. The loadings have negative values; therefore this factor is describing the lack of importance of the technical or technological aspects when using Agile methods from the Malaysian perspective. In this analysis, there is one loading in this factor ('our organisation emphasises on achievement and goal accomplishment where aggresiveness and winning are common themes') which is disregarded because it does not best describing the factor. Besides, it was considered that this variable should be excluded as it has less loading when compared to other variables in that factor. Therefore, the two negative loadings about the technical and technological aspects can be considered a sign of the 'Lack Importance of Technical and Technological Aspects when using Agile methods'.

7) Factor 7: This factor has two loadings which are describing the importance of sharing knowledge etc. The first loading- 'our organisational environment is a personal place where people share a lot of themselves' indicates the importance of sharing, or in orther words 'I agree sharing is important in the organisation'. On the other hand, a negative value in loading relating to 'In my experience, I think knowledge about Agile should be widely increased in the country', could be a sign of ' $I$ agree not enough knowledge about Agile methods in the country'. This reflects the importance of knowledge sharing about Agile methods in the country. All of these have supported the interpretation of factor 7 'The Importance of Sharing, Knowledge. etc'.

8) Factor 8: In the last component (factor 8), all the three loadings are describing the needs and results from well functioning teams. It is important for the team to know their roles and to have the right attitude when using Agile methods- as a result of this, quicker results can be gained. All three loadings have positive values. It also shows that knowing roles and responsibilities, and having the right attitude are important to get the benefits Agile can deliver (for example- quick results). Therefore, these loadings are best to be described as 'Team Commitment and Clarity of Purpose'.

\section{DISCUSSION AND CONCLUSION}

In this study, factor analysis for the 27 variables of Agile Adoption in Malaysia has been conducted. Following eigenvalue rules, eight factors were extracted and retained for further investigation. After the rotation is performed, the variables that were loaded into those eight factors are interpreted and they are defined as: (I) Factor 1: Developers' involvement and organisation-related aspect, (II) Factor 2: Organisational culture and people-related aspect, (III) Factor 3: Customers' involvement when using Agile methods, (IV) Factor 4: Benefits or impact when using Agile, (V) Factor 5: Disagreement over the importance of training and learning when using Agile methods in Malaysia, (VI) Factor 6: Lack of importance of the technical and technological aspects, (VII) Factor 7: Importance of knowledge, sharing, etc, (VIII) and lastly for Factor 8: Team commitment and clarity of purpose.

We found organisational and software developers' involvement as the top factor when using Agile methods. The adopters in this study were found to be from mixedrace teams and are using English in their daily business, thus proving that Agile can be practiced with difference races in a team. This result also shows that language is one of the important aspects when adopting Agile methods. In terms of the impact that Agile can deliver, high loadings (greater than 0.8) were found to be in customer satisfaction and the ease of software development as a result of collaboration between developers and customers.

\section{REFERENCES}

[1] B. Solemon, S. Sahibuddin, and A. A. A. Ghani, "Adoption of Requirements Engineering Practices in Malaysian Software Development Companies," Advances in Software Engineering, pp. 141-150.

[2] R. Sison, S. Jarzabek, O. S. Hock, W. Rivepiboon, and N. N. Hai, "Software practices in five ASEAN countries: an exploratory study," in Proceedings of the 28th international conference on Software engineering Shanghai, China: ACM, 2006.

[3] A. Field, Discovering statistics using SPSS (introducing statistical methods series): Sage, 2009.

[4] R. A. Kass, Tinsley, H.E.A (1979). "Factor Analysis," Journal of Leisure Research, vol. 11, pp. (120-138).

[5] E. Guadagnoli and W. F. Velicer, "Relation to sample size to the stability of component patterns," Psychological Bulletin, vol. 103, p. 265, 1988.

[6] H. F. Kaiser, "A Second Generation Little Jiffy," Psychometrika, vol. 35, pp. 401-415, 1970.

[7] H. F. Kaiser, "An ndex of Factorial Simplicity," Psychometrika, vol. 39, pp. 31-36, 1974.

[8] B. G. Tabachnick, Using Multivariate Statistics, 5th ed.: Pearson 2007.

[9] J. Pallant, SPSS Survival Manual: A Step by Step Guide to Data Analysis Using SPSS for Windows Version 15: Open University Press, 2007.

[10] D. De Vaus, Surveys in social research, 5th Edition ed.: Routledge, 2002. 